\title{
Descending thoracic and thoracoabdominal aortic aneurysms: "Busted"
}

\author{
Joseph S. Coselli, MD
}

\footnotetext{
From the Division of Cardiothoracic Surgery, Michael E. DeBakey Department of Surgery, Baylor College of Medicine, Houston, Tex; Adult Cardiac Surgery, Texas Heart Institute, Houston, Tex; and Adult Cardiac Surgery Section, Cardiovascular Service, Baylor St Luke's Medical Center, Houston, Tex.

Disclosures: Author has nothing to disclose with regard to commercial support.

Received for publication July 13, 2015; accepted for publication July 14, 2015; available ahead of print Aug 12, 2015.

Address for reprints: Joseph S. Coselli, MD, Division of Cardiothoracic Surgery, Michael E. DeBakey Department of Surgery, Baylor College of Medicine, One Baylor Plaza, BCM 390, Houston, TX 77030 (E-mail: jcoselli@bcm.edu).

J Thorac Cardiovasc Surg 2015;150:767-8

$0022-5223 / \$ 36.00$

Copyright (C) 2015 by The American Association for Thoracic Surgery

http://dx.doi.org/10.1016/j.jtcvs.2015.07.044
}

There is no doubt that aneurysms of the descending thoracic and thoracoabdominal aorta treated with open surgical techniques continue to have a significant morbidity and mortality with the ever-present risk of spinal cord ischemia and its pervading clinical consequences of paraplegia, bladder and bowel control, impotence, and skin breakdown. Despite these and other complications, increasing numbers of patients are being identified and subjected to lifesaving therapeutic intervention. ${ }^{1}$ The increase in identification and diagnosis in recent years is almost certainly due to the veritable ubiquitous availability of high-quality computed tomography scanning, especially in the emergency department environment. Improvements in treatment have been in part a direct consequence of the widespread adoption of organ-protection strategies, including distal aortic perfusion as left heart bypass or cardiopulmonary bypass, cerebrospinal fluid drainage, and motor evoked potential monitoring. ${ }^{2,3}$ Once these aneurysms rupture, the morbidity and mortality increase significantly in part because of the inability to apply these organ-specific protective strategies.

In this issue of the Journal, Dr Gaudino and colleagues ${ }^{4}$ report on their experience with 100 consecutive patients with descending thoracic and thoracoabdominal aneurysms repaired for rupture using open techniques. They exclude only those patients presenting with traumatic aortic rupture. This is reasonable considering the fact that thoracic endovascular aneurysm repair (TEVAR) has become the standard of care for traumatic aortic rupture. ${ }^{5}$ The authors present excellent results, with an operative mortality of only $14 \%$ in the ruptured group compared with a $4.2 \%$ mortality in the intact institutional cohort of 575 consecutive patients, and a spinal cord injury rate of only $5 \%$ in the ruptured cases and $2.4 \%$ in the intact group. In view of these excellent results, it is important to note that they are the product of a tertiary aortic referral

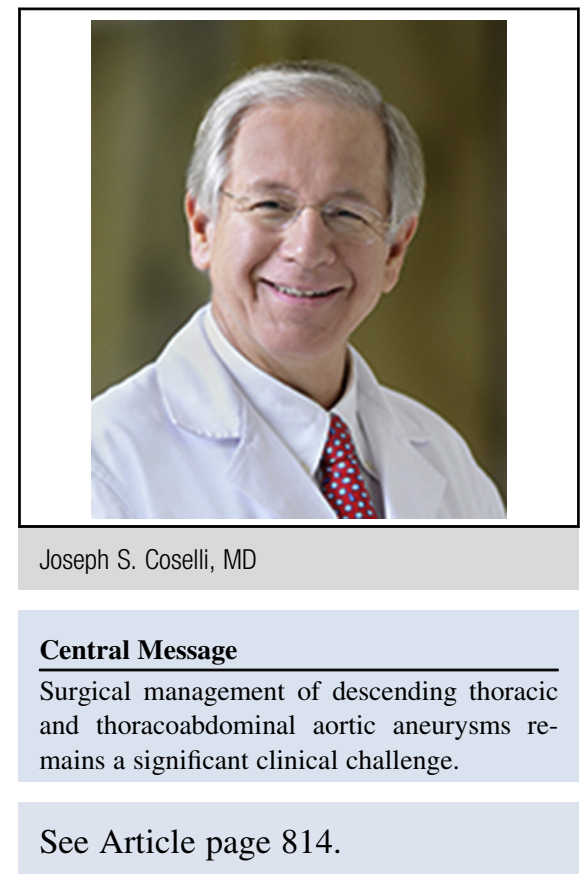

center caring for a large volume of patients with both descending thoracic and thoracoabdominal aortic aneurysms.

Gaudino and colleagues ${ }^{4}$ clearly make the point that much of the morbidity and mortality encountered after the open surgical treatment of ruptured thoracic aneurysms are consequences of the acute presentation not allowing for optimization of respiratory, renal, and coronary artery dysfunction, or other comorbidities. Although the authors' series does not include the use of TEVAR, they do note that TEVAR is notably attractive, particularly in the descending thoracic aneurysm group, in the emergency setting where surgeons and patients are faced with undiagnosed but significant comorbidities and their unpredictable influence on patient outcomes. Because TEVAR has become commonplace, even in smaller hospitals, patients who are referred to a high-volume aortic program such as that of the authors may have already bypassed those scenarios that are most easily or best managed by endovascular techniques. The subsequent choice of an open technique may have already been preordained by such a referral bias.

The authors clearly make the point that a successful surgical strategy, in the face of rupture contained or otherwise, requires significant judgment and individualization. Not all ruptures are created equal, and many are contained. Patients who are hemodynamically stable allow for the judicious 
application of organ-specific protection strategies, such as cerebrospinal fluid drainage, distal aortic bypass, and motor evoked potential monitoring. They also encourage the use of cerebrospinal fluid drainage at the conclusion of the procedure, if the possibility did not present itself at the initiation.

An entirely endovascular solution to thoracoabdominal aortic aneurysms is under development and on the horizon. ${ }^{6,7}$ Until off-the-shelf, noncustomizable endografts are widely available, the surgical skills necessary for the open treatment of descending thoracic and thoracoabdominal aortic aneurysms are going to be valuable particularly in the setting of rupture. An important aspect of this report by Gaudino and colleagues ${ }^{4}$ is that to obtain excellent results, particularly in emergency cases, a skilled surgeon is required, and equally important, is having a dedicated team devoted to a high-volume aortic program.

\section{References}

1. Kilic A, Shah AS, Black JH, Whitman GJ, Yuh DD, Cameron DE, et al. Trends in repair of intact and ruptured descending thoracic aortic aneurysms in the United States: a population-based analysis. J Thorac Cardiovasc Surg. 2014;147: 1855-60.

2. Coselli JS, Bozinovski J, LeMaire SA. Open surgical repair of 2286 thoracoabdominal aortic aneurysms. Ann Thorac Surg. 2007;83:S862-4; discussion S90-2.

3. Kouchoukos NT, Kulik A, Castner CF. Outcomes after thoracoabdominal aortic aneurysm repair using hypothermic circulatory arrest. J Thorac Cardiovasc Surg. 2013;145(3S):S139-41.

4. Gaudino MF, Lau C, Munjal M, Girardi LN. Open repair of ruptured descending thoracic and thoracoabdominal aortic aneurysm. J Thorac Cardiovasc Surg. 2015; 150:814-22.

5. Fox N, Schwartz D, Salazar JH, Haut ER, Dahm P, Black JH, et al. Evaluation and management of blunt traumatic aortic injury: a practice management guideline from the Eastern Association for the Surgery of Trauma. J Trauma Acute Care Surg. 2015;78:136-46.

6. Liao JM, Bakaeen FG, Cornwell LD, Simpson K, LeMaire SA, Coselli JS, et al. Nationwide trends and regional/hospital variations in open versus endovascular repair of thoracoabdominal aortic aneurysms. J Thorac Cardiovasc Surg. 2012;144:612-6.

7. Greenberg R, Eagleton M, Mastracci T. Branched endografts for thoracoabdominal aneurysms. J Thorac Cardiovasc Surg. 2010;140(6S):S171-8. 